\title{
Elevated Glucose Promotes Generation of Endothelium-derived Vasoconstrictor Prostanoids in Rabbit Aorta
}

\author{
Belay Tesfamariam, Michael L. Brown, ${ }^{\star}$ Daniel Deykin, ${ }^{\star}$ and Richard A. Cohen \\ Robert Dawson Evans Department of Clinical Research, Peripheral Vascular Section, Boston University, School of Medicine, \\ and ${ }^{*}$ Boston Veterans Administration Medical Center, Boston, Massachusetts 02118
}

\begin{abstract}
The effects of glucose on endothelium-dependent responses and vasoactive prostanoid production were determined by incubating isolated rabbit aortae in control $(5.5$ or $11 \mathrm{mM})$ or elevated (44 mM) glucose for $6 \mathrm{~h}$ to mimic euglycemic and hyperglycemic conditions. Rings of aortae incubated in elevated glucose, contracted submaximally by phenylephrine, showed significantly decreased endothelium-dependent relaxations induced by acetylcholine compared with the aortae incubated in control glucose. Treatment with indomethacin, a cyclooxygenase inhibitor, or SQ29548, a prostaglandin $\mathrm{H}_{2} /$ thromboxane $A_{2}$ receptor antagonist, restored acetylcholine relaxations of rings in elevated glucose to normal, while these agents had no effect on the relaxation of rings incubated in control glucose. Aortae incubated with mannose $(44 \mathrm{mM})$ as a hyperosmotic control relaxed to acetylcholine normally. The relaxations in response to $\mathrm{A} 23187$ and sodium nitroprusside were not different between rings exposed to control and elevated glucose. Radioimmunoassay measurements showed a significant increase in acetylcholine-stimulated release of thromboxane $A_{2}$ and prostaglandin $F_{2 \alpha}$ in aortae with, but not without endothelium incubated with elevated, but not with control glucose. Thus a possible mechanism for endothelium dysfunction in diabetes mellitus is the hyperglycemia-induced increased generation of endothelium-derived vasoconstrictor prostanoids. (J. Clin. Invest. 1990. 85:929-932.) acetylcholine - cyclooxygenase products • endothelium • hyperglycemia
\end{abstract}

\section{Introduction}

The endothelium contributes to the local regulation of vascular smooth muscle function by releasing endothelium-derived relaxing factors (EDRF), ${ }^{1}$ prostaglandins (PG) and enzymes that activate or degrade vasoactive hormones $(1,2)$. The integrity and function of the endothelial cell layer are profoundly altered in diabetic animals and man (3). Altered prostanoid production is among the many factors implicated in the patho-

Address reprint requests to Dr. Cohen, Peripheral Vascular Section, E-411, Boston University Medical Center, 88 East Newton Street, Boston, MA 02118.

Received for publication 7 August 1989 and in revised form 30 October 1989.

1. Abbreviations used in this paper: EDRF, endothelium-derived relaxing factors; PSS, physiological salt solution.

J. Clin. Invest.

(c) The American Society for Clinical Investigation, Inc.

0021-9738/90/03/0929/04 \$2.00

Volume 85, March 1990, 929-932 genesis of diabetic vascular disease (4-7). Recent evidence indicates that aortic rings from alloxan-induced diabetic rabbits with a mean plasma glucose of $20 \mathrm{mM}$ demonstrate an abnormal cholinergic receptor-mediated endothelium-dependent relaxation. The impaired relaxation is mediated by an increased production of vasoconstrictor prostanoids including thromboxane $A_{2}$ by the diabetic endothelium (4). Whether this abnormality results from hyperglycemia or hyperlipidemia associated with the diabetic experimental model is not known. These studies were undertaken to examine the direct effects of an elevated glucose milieu per se, on endothelium-dependent responses and prostanoid production by incubating isolated rabbit aortic rings in control or elevated glucose media. Our results indicate that exposure to an increased glucose concentration for $6 \mathrm{~h}$ can impair cholinergic endothelium-dependent relaxations by augmenting the production of vasoconstrictor prostanoids from the endothelium.

\section{Methods}

The abdominal aorta was dissected from male New Zealand white rabbits $(2.2-2.5 \mathrm{~kg})$ killed by exsanguination after anesthesia with pentobarbital sodium $(30 \mathrm{mg} / \mathrm{kg}$ i.v. $)$ and anticoagulation with heparin sodium ( $150 \mathrm{U} / \mathrm{kg}$ i.v.). The adhering perivascular tissue was carefully removed. Rings of aortae (5 $\mathrm{mm}$ long) were suspended from strain gauges for measurement of isometric circumferential force. The rings were placed in organ baths $(25 \mathrm{ml})$ filled with physiological salt solution (PSS) of the following composition (in $\mathrm{mM}$ ): $\mathrm{NaCl} 118.3, \mathrm{KCl} 4.7$, $\mathrm{MgSO}_{4}$ 0.6, $\mathrm{KH}_{2} \mathrm{PO}_{4} 1.2, \mathrm{CaCl}_{2} 2.5, \mathrm{NaHCO}_{3} 25.0$, and calcium ethylenediamine tetraacetic acid 0.026 . The solutions were maintained at $37^{\circ} \mathrm{C}$ and gassed with $95 \% \mathrm{O}_{2}-5 \% \mathrm{CO}_{2}$ to maintain $\mathrm{pH}$ at 7.4. Length of the smooth muscle was increased stepwise over 90 min to adjust basal tension to $6 \mathrm{~g}$. This was found to be optimal for contraction by testing repeated contractions to potassium $(80 \mathrm{mM})$. Thereafter, length was not altered. Aortic rings were then incubated in $5.5,11$, or $44 \mathrm{mM}$ glucose for $6 \mathrm{~h}$. Mannose (44 mM) was used as a hyperosmotic control. After the 6-h incubation the arteries were contracted with phenylephrine to $40-50 \%$ of their maximal contraction induced by potassium $(120 \mathrm{mM})$. When the contraction stabilized the responses to acetylcholine, A23187, and sodium nitroprusside were obtained by increasing bath concentration in half-log cumulative increments. Inhibitors were present during the 6-h incubations and during subsequent concentration-responses.

Radioimmunoassay. Segments of aortae $(2.5 \mathrm{~cm})$ were incubated in PSS and gently bubbled with $95 \% \mathrm{O}_{2}-5 \% \mathrm{CO}_{2}$ at $37^{\circ} \mathrm{C}$ for $6 \mathrm{~h}$ in control $(11 \mathrm{mM})$ or elevated $(44 \mathrm{mM})$ glucose. The PSS was changed every hour. Segments were prepared in which the endothelium was left intact or removed mechanically by gently rolling the segment on wet filter paper using forceps inserted into the lumen. At the end of the 6-h period the segments were incubated in PSS $(1 \mathrm{ml})$ sequentially in the absence and presence of acetylcholine $\left(10^{-6} \mathrm{M}\right)$ for $30 \mathrm{~min}$ each. The tissues were blotted dry and weighed. The incubates were frozen at $-80^{\circ} \mathrm{C}$ until analyzed. Radioimmunoassays were used to quantify the release of thromboxane $B_{2}$ (the stable hydrolytic product of thromboxane $A_{2}$ ), 6-keto-PGF $F_{1 \alpha}$ (the stable hydrolytic product of prostacy- 
clin), $\mathrm{PGF}_{2 \alpha}$, and $\mathrm{PGE}_{2}$ in the incubation buffers. Radioimmunoassays were performed using specific antisera of thromboxane $B_{2}$, $\mathrm{PGF}_{2 \alpha}$, and $\mathrm{PGE}_{2}$ (courtesy of Dr. Lawerence Levine, Brandeis University, Waltham, MA), 6-keto-PGF ${ }_{1 \alpha}$ (Biomol Research Laboratories, Inc., Plymouth, PA), tritiated standards (Dupont-NEN, Boston, MA), and unlabeled standards (UpJohn Co., Kalamazoo, MI; 8). Standard curves contained an equal volume of PSS to that being assayed and all dilutions were made with PSS. Cross-reactivity with other measured prostanoids was $<5 \%$. The limits of sensitivity for the radioimmunoassay with the experimental conditions described for thromboxane $\mathbf{B}_{2}$, 6-keto-PGF ${ }_{1 \alpha}$, and $\mathrm{PGF}_{2 \alpha}$ were $1 \mathrm{pg} / \mathrm{ml}$ and for $\mathrm{PGE}_{2}$ was $10 \mathrm{pg} / \mathrm{ml}$. Standard curves performed with the addition of glucose $(44 \mathrm{mM})$ were identical to those performed in control glucose.

Drugs. The pharmacological agents used were the following: acetylcholine chloride, calcium ionophore A23187, indomethacin, mannose, phenylephrine, and sodium nitroprusside (Sigma Chemical Co., St. Louis, MO), dazmegrel (Pfizer Inc., Groton, CT), ibuprofen and meclofenamate (Biomol Research Laboratories, Inc.), and SQ29548, a gift from Squibb Pharmaceuticals (Princeton, NJ). Concentrations were expressed as final molar bath concentrations. Unless otherwise specified, drugs were dissolved in distilled water such that volumes of $0.1 \mathrm{ml}$ were added to the organ bath. A23187 was prepared in ethanol $(95 \%)$. Indomethacin was prepared in $2 \% \mathrm{Na}_{2} \mathrm{CO}_{3}$ immediately before use. Stock solutions of SQ29548 were made in 95\% ethanol and further dilutions were made in PSS. Ibuprofen and meclofenamate were prepared in $0.1 \mathrm{~N} \mathrm{NaOH}$.

Data analysis. Maximal relaxation obtained in response to each concentration of agonist is expressed as percent change in the level of tone induced by phenylephrine. The $\mathrm{IC}_{50}$ was estimated graphically as the concentration causing 50\% relaxation of the induced tone. Data are expressed as means \pm SE. Statistical evaluation of the data was made using repeated measures of analysis of variance for concentration-response curves or Student's $t$ test for paired comparisons of responses of rings or release of prostanoids from arterial segments from the same animal. $P$ values $<0.05$ were regarded as significant. In all experiments, $n$ equals the number of rabbits from which rings were taken.

\section{Results}

Endothelium-dependent relaxations. Rings of aortae with intact endothelium incubated with $5.5,11$, or $44 \mathrm{mM}$ for $6 \mathrm{~h}$ were contracted with phenylephrine (concentration, $-\log \mathbf{M}$ : $6.5 \pm 0.5, n=5 ; 6.8 \pm 0.2, n=10$; and $6.7 \pm 0.1, n=10$; respectively) which caused similar contractions of $7.9 \pm 0.8,7.7 \pm 0.4$, and $7.2 \pm 0.4 \mathrm{~g}$, respectively. The rings were then exposed to increasing concentrations of acetylcholine $\left(10^{-8}-10^{-4} \mathrm{M}\right)$. The relaxations induced by acetylcholine were significantly decreased in aortic rings incubated with elevated $(44 \mathrm{mM})$ glucose compared with those in control $(5.5$ and $11 \mathrm{mM})$ glucose $\left(\mathrm{IC}_{50}-\log \mathrm{M}: 6.4 \pm 0.2(n=10)\right.$ vs. $7.2 \pm 0.1(n=5)$ and $7.2 \pm 0.1$ $(n=10)$, respectively, $P<0.05$, Figs. 1,2$)$. The relaxations caused by acetylcholine were not significantly different between rings incubated in 5.5 and $11 \mathrm{mM}$ glucose. Relaxations caused by acetylcholine $\left(3 \times 10^{-7}-10^{-4} \mathrm{M}\right)$ were followed by recontractions of aortae incubated in elevated, but not in control glucose (Fig. 1). Aortae incubated with mannose (44 mM) for $6 \mathrm{~h}$ relaxed to acetylcholine normally $\left(\mathrm{IC}_{50}-\log \mathrm{M}\right.$ : $7.2 \pm 0.1, n=4)$. Aortae incubated in elevated glucose contracted with $\mathrm{PGF}_{2 \alpha}$ instead of phenylephrine showed similar impaired acetylcholine-induced relaxations (data not shown).

Treatment with indomethacin, meclofenamate or ibuprofen $\left(10^{-5} \mathrm{M}\right)$ restored acetylcholine relaxations of rings incubated with elevated glucose $\left(\mathrm{IC}_{50}-\log \mathrm{M}: 7.3 \pm 0.1, n=6\right.$, $7.2 \pm 0.1, n=4$ and $7.2 \pm 0.1, n=4$, respectively), such that the relaxations did not differ statistically from those observed in
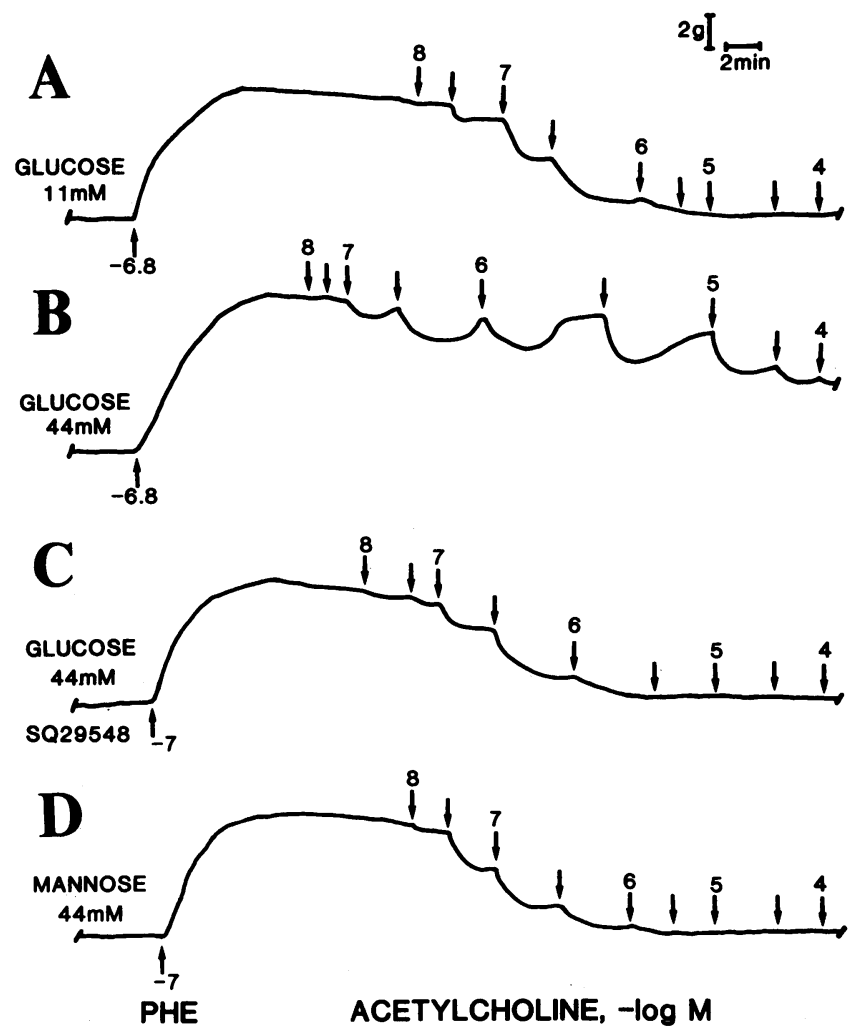

Figure 1. Tracings of rings of aortae contracted with phenylephrine (PHE) and then exposed to half-molar increases in concentration of acetylcholine. Aortae incubated for $6 \mathrm{~h}$ in control glucose (11 mM) show normal relaxations $(A)$, but those incubated in elevated glucose $(44 \mathrm{mM})$ show decreased relaxations to acetylcholine $(B)$. Treatment with SQ29548 $\left(3 \times 10^{-6} \mathrm{M}\right)$ normalized the abnormal responses in aortae incubated in elevated glucose $(C)$. Aortae incubated in mannose $(44 \mathrm{mM})$, to serve as a hyperosmotic control, relaxed to acetylcholine normally $(D)$.

rings incubated in control glucose. Similarly, treatment with SQ29548 $\left(3 \times 10^{-6} \mathrm{M}\right)$ restored acetylcholine relaxations of rings incubated in elevated glucose to normal $\left(\mathrm{IC}_{50},-\log \mathrm{M}\right.$ : $7.0 \pm 0.1, n=4)$. Neither the cycloxygenase inhibitors nor SQ29548 had a significant effect on the relaxation to acetylcholine of rings incubated with control glucose (Fig. 2). In rings of aortae incubated in elevated glucose, treatment with dazmegrel $\left(3 \times 10^{-6} \mathrm{M}\right)$ did not significantly affect the abnormal relaxations caused by acetylcholine $\left(\mathrm{IC}_{50}-\log \mathrm{M}\right.$ : $6.2 \pm 0.2, n=3$ ).

The relaxations caused by $\mathrm{A} 23187\left(10^{-8}-3 \times 10^{-6} \mathrm{M}\right)$ were not significantly different between rings incubated in control $(11 \mathrm{mM})$ or elevated $(44 \mathrm{mM})$ glucose. The maximal relaxation caused by $\mathrm{A} 23187\left(3 \times 10^{-6} \mathrm{M}\right)$ was $34 \pm 5.6$ vs. $37 \pm 5.4 \%$, respectively, $(n=5)$.

Endothelium-independent relaxations. The relaxations caused by sodium nitroprusside $\left(10^{-9}-10^{-5} \mathrm{M}\right)$ were not significantly different between rings incubated in control $(11 \mathrm{mM})$ or elevated $(44 \mathrm{mM})$ glucose $\left(\mathrm{IC}_{50}-\log \mathrm{M}: 8.0 \pm 0.2\right.$ vs. $8.0 \pm 0.1$, respectively, $n=5$ ).

Prostanoid production. Under basal conditions or in the presence of acetylcholine $\left(10^{-6} \mathrm{M}\right)$, the production of the prostanoids, thromboxane $\mathrm{B}_{2}, 6-$ keto-PGF $_{1 \alpha}, \mathrm{PGF}_{2 \alpha}$, and $\mathrm{PGE}_{2}$, was significantly greater in segments with, than in seg- 


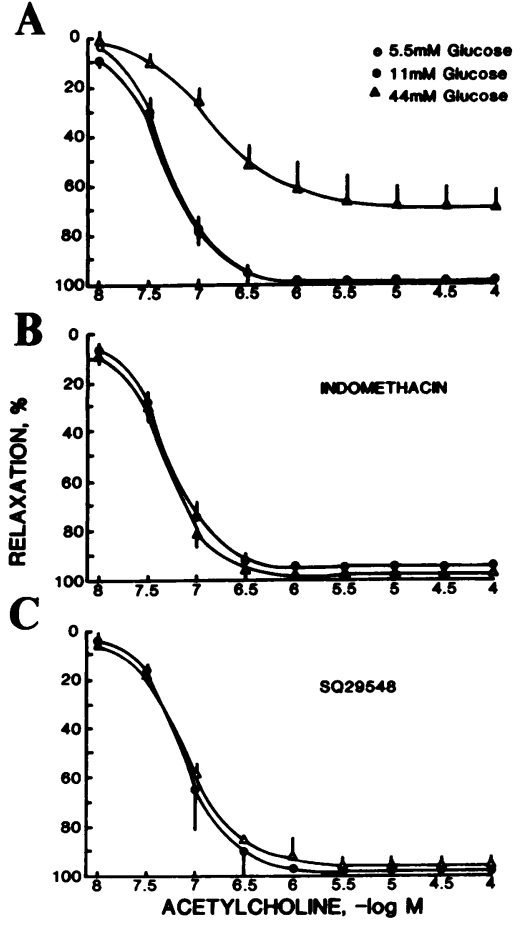

tylcholine-induced relaxations in aortic rings incubated in elevated glucose such that the relaxations were not significantly different from those in control glucose. Neither inhibitor affected the response of aortae in control glucose. Values are shown as means \pm SE.

ments without endothelium (Table I). There was no significant difference in the production of any of the prostanoids in the presence of control $(11 \mathrm{mM})$ or elevated $(44 \mathrm{mM})$ glucose under basal conditions, in the presence or absence of endothelium. Acetylcholine $\left(10^{-6} \mathrm{M}\right)$ significantly increased all of the measured prostanoids in the presence of normal or elevated glucose in segments with endothelium, as well as increased 6-keto-PGF $\mathrm{P}_{1 \alpha}$ production in segments without endothelium. In the presence of acetylcholine, the production of thromboxane $B_{2}$ and $P F_{2 \alpha}$ by segments with, but not without endothelium was significantly greater in the presence of elevated glucose compared with control, whereas that of 6-keto-PGF - $_{1 \alpha}$ and $\mathrm{PGE}_{2}$ was not significantly affected.

In the presence of dazmegrel $\left(3 \times 10^{-6} \mathrm{M}\right)$, the release of thromboxane $B_{2}$ from aortae incubated in elevated glucose under basal conditions or in the presence of acetylcholine $\left(10^{-6} \mathrm{M}\right)$ was significantly inhibited $(1.8 \pm 0.3$ and $2.2 \pm 0.3$ $\mathrm{pg} / \mathrm{mg}$ per $30 \mathrm{~min}$, respectively, $n=3$ ).

\section{Discussion}

The present experiments performed after exposure to conditions that mimic pronounced hyperglycemia demonstrate impairment of endothelium-dependent acetylcholine-induced relaxation by stimulated production of endothelium-derived vasoconstrictor factor(s). The abnormal relaxations observed after incubating with elevated glucose for $6 \mathrm{~h}$ was a time-dependent effect because incubation for 2 or $3 \mathrm{~h}$ in elevated glucose caused a less pronounced abnormality (unpublished observations). The alterations caused by elevated glucose are not due to a hyperosmotic effect because the same concentra-
Table I. Basal and Acetylcholine-stimulated Release of Immunoreactive Prostanoids from Aortic Segments with and without Endothelium Incubated in Control and Elevated Glucose

\begin{tabular}{|c|c|c|c|c|}
\hline \multicolumn{3}{|c|}{ With endothelium } & \multicolumn{2}{|c|}{ Without endothelium } \\
\hline Glucose: & Control & Elevated & Control & Elevated \\
\hline \multicolumn{5}{|l|}{ Thromboxane $B_{2}$} \\
\hline Basal & $8.5 \pm 1.1^{\ddagger}$ & $8.2 \pm 1.4^{\ddagger}$ & $5.7 \pm 0.7$ & $4.3 \pm 0.3$ \\
\hline Acetylcholine & $14 \pm 1.8^{\ddagger 8}$ & $29 \pm 4.3^{* \neq \S}$ & $6.0 \pm 1.0$ & $7.6 \pm 1.4$ \\
\hline \multicolumn{5}{|l|}{$\mathrm{PGF}_{2 \mathrm{a}}$} \\
\hline Basal & $61 \pm 6.2^{\ddagger}$ & $94 \pm 18^{\ddagger}$ & $49 \pm 7.2$ & $56 \pm 10$ \\
\hline Acetylcholine & $152 \pm 26^{\ddagger \S}$ & $193 \pm 29^{* \neq \S}$ & $65 \pm 12$ & $79 \pm 10$ \\
\hline \multicolumn{5}{|l|}{ 6-keto-PGF ${ }_{1 \mathrm{a}}$} \\
\hline Basal & $201 \pm 67^{\ddagger}$ & $273 \pm 54^{\ddagger}$ & $53 \pm 4.8$ & $38 \pm 3.8$ \\
\hline Acetylcholine & $937 \pm 164^{\ddagger \S}$ & $963 \pm 88^{\ddagger \S}$ & $146 \pm 37^{\S}$ & $156 \pm 44^{\S}$ \\
\hline \multicolumn{5}{|l|}{$\mathrm{PGE}_{2}$} \\
\hline Basal & $99 \pm 22^{\ddagger}$ & $101 \pm 27^{\ddagger}$ & $52 \pm 22$ & $56 \pm 6.8$ \\
\hline Acetylcholine & $219 \pm 40^{\ddagger \S}$ & $215 \pm 52^{\ddagger \S}$ & $76 \pm 23$ & $83 \pm 5.3$ \\
\hline
\end{tabular}

Values are expressed as means $\pm \mathrm{SE}(\mathrm{pg} / \mathrm{mg}$ tissue per $30 \mathrm{~min})$. The weights of the rabbit aortae used for control and elevated glucose incubations were $44 \pm 5.1$ and $49 \pm 6.8 \mathrm{mg}$ (with endothelium, $n=6$ ) and $46 \pm 3.1$ and $44 \pm 3.8$ (without endothelium, $n=3$ ), respectively. * Indicate significant difference between prostanoid production in control and elevated glucose.

‡Indicate significantly greater release from segments with endothelium compared to that from those without endothelium.

\& Indicate significant increase caused by acetylcholine $\left(10^{-6} \mathrm{M}\right)$ compared with basal.

tion of mannose had no effect on the relaxations induced by acetylcholine. The cyclooxygenase inhibitors, indomethacin, meclofenamate, and ibuprofen, restored acetylcholine-induced relaxations suggesting that the inhibition was mediated by a cyclooxygenase product produced in the presence of elevated glucose. The restoration of acetylcholine-induced relaxation by the vasoconstrictor prostanoid receptor antagonist, SQ29548 (9), is consistent with mediation by prostaglandin endoperoxides or their derivatives, including thromboxane $A_{2}$ and $\mathrm{PGF}_{2 \alpha}$.

A role for these vasoconstrictor prostaglandins is further supported by radioimmunoassay measurements. In these experiments elevated glucose induced rapid alterations in arachidonate metabolites produced during stimulation with acetylcholine yielding increased amounts of thromboxane $\mathrm{A}_{2}$ and $\mathrm{PGF}_{2 \alpha}$. Cholinergic agents have been shown to also stimulate prostacyclin and $\mathrm{PGE}_{2}$ synthesis by the endothelium of rabbit aorta $(10,11)$. It is less likely that prostacyclin or $\mathrm{PGE}_{2}$ contribute to the abnormal relaxation to acetylcholine because the stimulated release of these prostanoids was independent of glucose concentration in the medium, and both are less potent vasoconstrictors of the rabbit aorta compared with the thromboxane $\mathrm{A}_{2}$ mimetic, $\mathrm{U} 46619$, or $\mathrm{PGF}_{2 \alpha}$ (4).

Experiments with pharmacological antagonists as well as radioimmunoassay measurements point to vasoconstrictor prostaglandins including thromboxane $\mathrm{A}_{2}$ and $\mathrm{PGF}_{2 \alpha}$ as the mediators of the abnormal acetylcholine response. A major role for thromboxane $A_{2}$ in the abnormal acetylcholine-mediated relaxation is less likely as suggested by the failure of the thromboxane synthase inhibitor, dazmegrel (12), to correct the 
response. Increased production of prostaglandin endoperoxides could cause the abnormal acetylcholine response of aorta exposed to elevated glucose because the vasoconstriction which they cause is blocked by SQ29548 (9) and their formation is not prevented by dazmegrel (12). The preferential synthesis of more potent vasoconstrictor endoperoxide-derived prostanoids may also favor their direct role in the impaired relaxation to acetylcholine.

The relaxations induced by sodium nitroprusside, an endothelium-independent vasodilator which relaxes smooth muscle by a mechanism similar to that of EDRF (13), as well as that to the calcium ionophore A23187, a non-receptor-mediated endothelium-dependent vasodilator, were not different between aortae in control or elevated glucose. This suggests that the release, or responsiveness of the smooth muscle to EDRF is not altered by elevated glucose. A major finding in this study is that elevated glucose enhances release of vasoconstrictor prostanoids following cholinergic stimulation, and the endothelium is its source. This is supported by the normal basal release of prostanoids in aortae with endothelium and by the normalization of acetylcholine-stimulated prostanoid production after removal of the endothelium.

The present findings complement the findings in isolated aortae of alloxan-induced diabetic rabbits, which showed impaired endothelium-dependent relaxations induced by acetylcholine that were corrected by cyclooxygenase inhibition or SQ29548 and were associated with increased thromboxane $A_{2}$ production (4). Others have reported that endothelium-dependent relaxations to acetylcholine are impaired in aortae of streptozotocin-induced diabetic rat and in the spontaneously diabetic BB Wistar rat (14-16). Additionally, decreased endothelium-dependent relaxations to acetylcholine have been reported in isolated penile corpus cavernosum tissue of impotent diabetic men (17). Thus, the present studies suggest that by varying the glucose concentration in the medium, a useful in vitro model is achieved for studying the changes in endothelial cell vasodilator function as well as prostanoid production seen in diabetic animals and man. In experimental diabetes, hyperlipidemia and elevated cholesterol similar to that seen in diabetic patients have been reported to increase platelet thromboxane $A_{2}$ generation $(18,19)$. The present study provides evidence that elevated plasma glucose per se may be a primary factor for the increased production of vasoconstrictor prostanoids by the endothelium. The observation that glucose can readily contribute to changes in the function of the endothelium by inducing generation of vasoconstrictor prostaglandins in response to cholinergic stimulation suggests that production of these prostanoids during hyperglycemia may contribute to vascular complications in diabetes mellitus.

\section{Acknowledgments}

The authors thank Marie Ryan for preparing the figures.

The work was supported by National Institutes of Health grants HL-38731, HL-31607, DK-39624 and a grant from the Veterans Administration Medical Research Service. B. Tesfamariam is supported by a Fellowship Grant from the Juvenile Diabetes Foundation International. R. A. Cohen is the recipient of an Established Investigator Award from the American Heart Association.

\section{References}

1. Furchgott, R. F., and J. V. Zawadzki. 1980. The obligatory role of the endothelial cells in the relaxation of arterial smooth muscle by acetylcholine. Nature (Lond.). 288:373-376.

2. Moncada, S., and J. R. Vane. 1977. Prostacyclin $\left(\mathrm{PGI}_{2}\right)$, the vascular wall and vasodilation. In Mechanisms of vasodilation. P. M. Vanhoutte and I. Leusen, editors. S. Karger, Basel. 107-121.

3. Ruderman, N. B., and C. Haudenschild. 1984. Diabetes as an atherogenic factor. Prog. Cardiovasc. Res. 26:373-412.

4. Tesfamariam, B., J. A. Jakubowski, and R. A. Cohen. 1989. Contraction of diabetic rabbit aorta due to endothelium-derived $\mathrm{PGH}_{2} / \mathrm{TXA}_{2}$. Am. J. Physiol. 257:H1327-H1333.

5. Gerrad, J. M., M. J. Stuart, G. H. R. Rao, M. W. Steffes, S. M Mauer, D. M. Brown, and J. G. White. 1980. Alteration in the balance of prostaglandin and thromboxane synthesis in diabetic rats. J. Lab. Clin. Med. 95:950-958.

6. Sulbiah, M. T. R., and D. Deitemeyer. 1980. Altered synthesis of prostaglandins in platelet and aorta from spontaneously diabetic wistar rats. Biochem. Med. 23:231-235.

7. Quilley, J., and J. C. McGiff. 1985. Arachidonic acid metabolism and urinary excretion of prostaglandins and thromboxane in rats with experimental diabetes mellitus. J. Pharmacol. Exp. Ther. 234:211216.

8. Jakubowski, J. A., M. J. Stampfer, R. Vaillancourt, and D. Deykin. 1985. Cummulative antiplatelet effect of low-dose enteric coated aspirin. Br. J. Haematol. 60:635-642.

9. Ogletree, M. L., D. N. Harris, R. Greenberg, M. F. Haslanger, and M. Nakane. 1985. Pharmacological actions of SQ29548, a novel selective thromboxane antagonist. J. Pharmacol. Exp. Ther. 234:435441.

10. Beetens, J. R., C. V. Hove, M. Rampart, and A. G. Herman. 1983. Acetylcholine stimulates the release of prostacyclin by rabbit aorta endothelium. J. Pharm. Pharmacol. 35:251-252.

11. Boeynaems, J. M., and N. Galand. 1983. Cholinergic stimulation of vascular prostacyclin synthesis. Prostaglandins. 26:531-544.

12. Truog, W. E., G. K. Sorensen, T. A. Standaert, and G. S. Redding. 1986. Effects of the thromboxane synthase inhibitor Dazmegrel (UK38485) on pulmonary gas exchange and hemodynamics in neonatal sepsis. Pediatr. Res. 20:481-486.

13. Rappoport, R. M., and F. Murad. 1983. Agonist-induced endothelium dependent relaxation in rat thoracic aorta may be mediated through cGMP. Circ. Res. 52:352-357.

14. Oyama, Y., H. Kawasaki, Y. Hattori, and M. Kanno. 1986. Attenuation of endothelium-dependent relaxation in aorta from diabetic rats. Eur. J. Pharmacol. 131:75-78.

15. Meraji, S., L. Jayakody, M. P. Senaratne, A. B. R. Thomson, and T. Kappagoda. 1987. Endothelium-dependent relaxation in aorta of BB rat. Diabetes. 36:978-981.

16. Wakabayashi, I., K. Hatake, N. Kimura, E. Kakishita, and K. Nagai. 1987. Modulation of vascular tonus by the endothelium in experimental diabetes. Life Sci. 40:643-648.

17. Saenz de Tejada, I., I. Goldstein, K. Azadzoi, R. Krane, and R. Cohen. 1989. Impaired neurogenic and endothelium-dependent relaxation of human penile smooth muscle: the pathophysiological basis for impotence in diabetes mellitus. $N$. Engl. J. Med. 320:1025-1030.

18. Sinzinger, H., J. Kaliman, K. Klein, and K. Silberbauer. 1980. Vascular prostacyclin synthesis, platelet sensitivity, plasma factors and platelet function in patients with peripheral occlusion arteriopathy with and without diabetes mellitus. In Diet and Drugs in Atherosclerosis. G. Noseda, I. Lewis, and S. Paoletti, editors. Raven Press, New York. 93-98.

19. Turek, J. V., U. M. Houtsmeller, R. N. Lussemburg, and G. J. den Onolander. 1980. Effect of low cholesterol, linoleic acid enriched diet or thrombotic tendency and plasma lipoproteins in patients with angina pectoris. Artery. 8:134-140. 